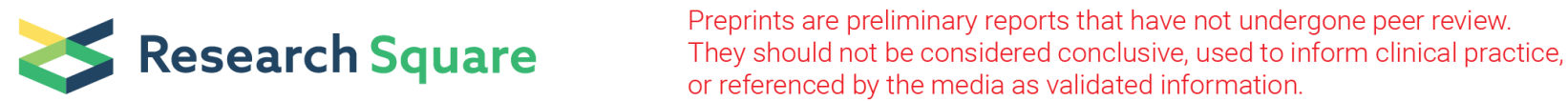

\section{Application of Rapid Rehabilitation Concept in Enhanced Recovery After Cesarean Section in Patients With Gestational Diabetes Mellitus: a Systematic Review}

\author{
Aiwen Jian \\ Shandong University \\ Qiuhong Yang ( yqh18053153320@126.com) \\ Jinan Maternity and Child Care Hospital
}

\section{Research Article}

Keywords: gestational diabetes mellitus, enhanced recovery after surgery, cesarean section, maternalneonatal complications

Posted Date: September 20th, 2021

DOl: https://doi.org/10.21203/rs.3.rs-886638/v1

License: (c) (i) This work is licensed under a Creative Commons Attribution 4.0 International License. Read Full License 


\section{Abstract}

Background: Gestational diabetes mellitus (GDM) is defined as all cases of diabetes observed during gestation, including pre-gestational diabetes and true GDM with its first onset during pregnancy. A rising number of parturient are diagnosed with GDM due to increased maternal weight, creating a serious global health concern. In order to improve maternal health and reduce childhood mortality, rapid rehabilitation approaches for postpartum recovery are of significant importance. However, most guidelines regarding this area remains extremely limited with poor quality,

Methods: All the references included in this work were either in English or in Chinese, enrolled via systematic selection from database PubMed, Web of Science (WOS) and CNKI. "Gestational diabetes mellitus", "rehabilitation", "cesarean", "neonatal diabetes mellitus" etc. were selected as keywords during the search. No restriction was placed on publish date, quality or the setting of the studies.

Results: A total of 666 literatures were found in the initial selection. After sorting out 130 duplications, 536 articles had titles and abstracts read, among which 70 were thoroughly read. The contents of the articles include maternal-neonatal complications of GDM, maternal health managements in antenatal period, during labor and postpartum period, providing descriptions of maternal and neonatal outcomes after GDM patients receiving the interventions.

Conclusions: The application of rapid rehabilitation concept in enhanced recovery of cesarean section in pregnant women with GDM during perioperative period can significantly reduce the risk of multiple maternal-neonatal complications. However, the studies focusing on the discovery of new rapid rehabilitation approaches are still inadequate.

\section{Introduction}

Gestational diabetes mellitus (GDM) refers to any degree of either hyperglycemia or diabetes with onset or first recognition during pregnancy, induced by transitory form of glucose intolerance and pancreatic $\beta$ cell dysfunction, and remains below the cut-off value for manifest diabetes. ${ }^{1,2}$ It has become one of the most frequently diagnosed pregnancy complications in clinic, with the incidence rate of 9.0-25.1\% worldwide, an average of $14.0 \%,{ }^{3,4}$ yet the global prevalence is still on the rise. ${ }^{5} \mathrm{GDM}$ without appropriate antenatal and postpartum managements results in various severe maternal and fetal complications, such as premature delivery, fetal macrosomia and intrauterine growth retardation (IUGR). ${ }^{6}$ Pregnant women with GDM and their neonates are identified to be predisposed to metabolic diseases including obesity, hyperglycemia and eventually type 2 diabetes mellitus (T2DM). ${ }^{7}$ In addition, health economic consequences of GDM in pregnant women and related maternal-fetal complications are noticed, indicating direct substantial health-economic burden. ${ }^{8}$

Most importantly, as GDM usually accompanies preeclampsia, shoulder dystocia and fetal macrosomia, ${ }^{9}$ if not applied with timely and effective intervention, maternal and neonatal health would be put in danger. 
To guarantee the safety of parturient with GDM and the neonate, the use of cesarean section is remarkably enhanced. The overall cesarean section rate in pregnant women with GDM is significantly higher than that in nondiabetic pregnant women, as well as the acute cesarean section rate, which is 1.52 times the nondiabetic one is. ${ }^{10,11}$ However, cesarean section poses an enormous threat of surgical incision infection and maternal post-operative wound infection to pregnant women with GDM. ${ }^{12}$ It is urgent to achieve rapid rehabilitation for post-cesarean section parturient. Fortunately, the outcome of GDM can be improved via standardized and appropriate managements, by significantly lessen the severity of maternal and natal complications, according to recent studies. ${ }^{13}$ Therefore, standardized management of postpartum recovery in pregnant women with GDM is of great significance in levitation and prevention of the related complications and subsequent diseases.

At the present stage, numerous clinical guidelines on the rapid rehabilitation approach after cesarean section in nondiabetic pregnant women have been published. ${ }^{14}$ Surprisingly, we found that there was not even one guideline regarding the postpartum rapid rehabilitation of pregnant women with GDM. In order to fill this gap, this review focuses on the maternal and natal adverse effects accompany the cesarean section in pregnant women with GDM and the application of rapid rehabilitation concept in perioperative care of cesarean section with GDM, which also aims to build the foundation for subsequent studies and encourage fellow researchers to pay more attention to this field.

\section{Methods}

\section{Inclusion and exclusion criteria}

Inclusion criteria: 1) the language used in the paper was English or Chinese; 2) studies involving perioperative management strategies for maternal and neonatal complications of GDM; 3 ) studies involving pregnant women suffered cesarean section with GDM; 4) reported perioperative outcomes, such as blood glucose level, adverse effects etc.

Exclusion criteria: 1) non-English and Chinese published literature; 2) not related to post-cesarean section rehabilitation

\section{Literature search}

A systematic selection was conducted in three distinct database, PubMed, Web of Science (WOS) and $\mathrm{CNKI}$, focusing on studies related to "application of rapid rehabilitation concept in postpartum recovery of cesarean section in pregnant women with gestational diabetes mellitus". However, no direct result was found associating this aspect. Thus, a second round of selection was conducted, using the following strings in PubMed MeSH:

"diabetes, gestational/complications"[MeSH Major Topic] OR "diabetes, gestational/diet therapy"[MeSH Major Topic] OR "diabetes, gestational/drug therapy"[MeSH Major Topic] OR "diabetes, gestational/metabolism"[MeSH Major Topic] OR "diabetes, gestational/nursing"[MeSH Major Topic] OR 
"diabetes, gestational/therapy"[MeSH Major Topic]) AND ("caesarean"[All Fields] OR "caesareans"[All Fields] OR "cesarean"[All Fields] OR "cesareans"[All Fields] and in WOS: "gestational diabetes mellitus (Topic) and neonatal (Topic) and cesarean (Topic)".

No restriction was placed on the settings and quality of the studies, and no time range was set. All citations were imported into EndNote for further screening.

\section{Screening of studies}

The studies selected were screened according to the following three steps. First, all duplicates were found and removed using EndNote; second, all the directly or partially related studies were selected by reviewing the titles and abstracts; finally, the full texts of the selected papers were read.

\section{Results}

A total of 666 literatures were identified in the initial search. After 130 duplicates were removed, 536 records' titles and abstracts were reviewed and 70 articles were retrieved full-text reviewing. The publish dates range from 1954 to 2021 , most of which were published in the recent decade.

\section{Discussion}

\section{Adverse maternal outcomes}

Hypertensive disorders: Hypertensive disorders during pregnancy and postpartum period are classified into three pathological categories: chronic hypertension, pre-eclampsia and gestational hypertension, which are all recognized as risk factors of subsequent diseases, such as T2DM, metabolic disorders and CVD. ${ }^{15}$ Several studies indicated that GDM contributes to the onset of hypertension during pregnancy and postpartum period. ${ }^{16}$ Hyperglycemia, as a characteristic of GDM, can damage endothelial cells, resulting in vascular hypertensive dysfunction. ${ }^{17,18}$ In addition, hyperinsulinemia in patients with GDM that influences weight gain and renal sodium retention, is also a nonnegligible risk factor for developing hypertension. ${ }^{19}$ For the purpose of resolving the questions regarding the optimal diagnostic cutpoints of GDM, the National Institutes of Health and other health care organizations sponsored and launched an international prospective cohort study, termed HAPO. ${ }^{20}$ The HAPO study suggested that pregnant women who were obese with GDM and high BMI, had risks of developing pre-eclampsia higher than normal women by eight folds. ${ }^{20,21}$ However, contradictory results were observed in a recent retrospective study, demonstrating GDM and chronic hypertension could be protective against the development of preeclampsia and gestational hypertension. ${ }^{21}$

Preterm birth: Infants born alive prior to 37-week gestation are recognized as preterm births. ${ }^{20,22}$ Pregnant women with GDM face a frequency of $6.9 \%$ of encountering preterm birth, which was demonstrated to be in correlation with increased post oral glucose tolerance test (OGTT) maternal glucose. ${ }^{20}$ 
Cesarean section: Due to the requirement to overcome one or several adverse complications with GDM, such as shoulder dystocia and fetal macrosomia, cesarean section is commonly applied to patients with GDM, to guarantee the safety of parturient and neonate. According to a cross-section study, the most frequent maternal complications were induction of labor (66\%) and cesarean section (32\%). Among women went through labor induction, the majority (81\%) proceeded to have a cesarean section. ${ }^{23}$ The frequency of cesarean section application in patients with GDM is indicated to be associated with increased post OGTT maternal glucose and fasting glucose levels. ${ }^{20}$ It bears high risk of wound infection, hemorrhage, thrombosis and wound dehiscence. ${ }^{24}$ In addition, recent study shows that despite reduced neonates' birth weight, cesarean sections are still conducted in patients with GDM, which suggests that GDM alone can be an indicator for cesarean section. ${ }^{25}$

Long-term metabolic comorbidities: GDM with no intervention conducted significantly increases the lifetime risk of developing type 2 diabetes mellitus (T2DM) ${ }^{26,27}$ Approximately $50 \%$ of women with a history of GDM will develop T2DM within a decade. ${ }^{28} \mathrm{~A}$ strong correlation between increasing prepregnancy $\mathrm{BMI}$, higher fasting glucose level, early gestational age at GDM diagnosis and post-partum impaired glucose tolerance, and subsequent onset of T2DM, was observed in recent studies. ${ }^{28}$ Furthermore, an estimated frequency of one-third of the female patients with T2DM has a history of GDM, indicating that GDM could be a convincing predictor of subsequent T2DM. ${ }^{29}$

\section{Adverse neonatal outcomes}

Neonatal hypoglycemia: Occurs in around $2.1 \%$ of the offspring of patients with GDM, as a result of fetal hyperinsulinemia responding to exposure to high glucose level from the mother. ${ }^{24}$ The risk of neonatal hypoglycemia is considered in correlation with increased post OGTT maternal glucose instead of fasting glucose levels. ${ }^{20}$ In addition, some neurological sequelae might be induced by the nadir glucose concentration and the duration of neonatal hypoglycemia. ${ }^{30}$

Hyperbilirubinemia: Increased maternal blood glucose level and subsequent fetal hyperinsulinemia decrease fetal oxygen consumption, resulting in increased fetal red cell mass, which may be responsible for subsequent hyperbilirubinemia. ${ }^{24}$ An estimated frequency of $8.3 \%$ of offspring of GDM patients was founded with hyperbilirubinemia. However, this comorbidity is relatively less associated with maternal OGTT glucose levels. ${ }^{20}$

Fetal macrosomia: Recent study indicated that $24.7 \%$ of GDM patients had neonates with macrosomia (birthweight $>4 \mathrm{~kg}$ ), and those with a previous baby weight $>4 \mathrm{~kg}$ were facing higher risks of having further babies with fetal macrosomia. ${ }^{23}$ It is assumed as a consequence of fetal hyperinsulinemia and increased umbilical C-peptide in responding to increased trans-placental flow of glucose from the mother. ${ }^{31}$

Neonatal hypocalcemia: Low maternal vitamin D status and hypomagnesemia of GDM patients may be a reason for the cause of neonatal hypocalcemia. ${ }^{32}, 33$ Nevertheless, the frequency of hypocalcemia in 
neonates of women with GDM remains relatively low and of little clinical importance.

Other comorbidities in neonates of GDM patients includes respiratory distress syndrome, ${ }^{34}$ hypertrophic cardiomyopathy ${ }^{35}$ and major congenital malformations ${ }^{36}$, which were found to be less frequent.

Long-term metabolic comorbidities: It is noticed that offspring of mothers with GDM are at increased risks of developing T2DM, obesity, cardiovascular diseases and structural hypothalamic changes. ${ }^{37}$ In a follow-up study of adult offspring of women with GDM, the risk of prediabetes/diabetes and metabolic syndrome was eight and four folds higher than that of offspring of background population. ${ }^{28}$ Evidences are that the development of subsequent T2DM in offspring is associated with fetal $\beta$-cell hypertrophy, relatively impaired insulin secretion and impaired insulin sensitivity resulted from fetal exposure to intrauterine hyperglycemia. $27,31,38$

\section{Enhanced Recovery After Surgery (ERAS) managements}

Enhanced Recovery After Surgery (ERAS) protocols has made remarkable progress in the field of surgery in recent years, though the literature search in this work indicated the lack of research papers and standardized guidelines regarding the application of ERAS protocols to cesarean section with GDM. ERAS is not a fixed operation process. Instead, it is a multidisciplinary, multi-pattern perioperative rehabilitation concept based on evidence-based medicine, continuously optimizing the operation plan in each diagnostic and treatment process, including outpatient evaluation, preoperative preparation, intraoperative management and postoperative rehabilitation, and the clinical effect examination.

\section{Antenatal managements}

Studies have demonstrated adverse maternal and neonatal outcomes of most women (80\%-90\%) with GDM can be significantly reduced through effective intervention, such as dietary management and exercise. ${ }^{39-41}$ Screening and lifestyle management are two important factors for improvement of maternal and neonatal health. According to a guideline for the diagnosis and treatment of GDM developed by the Department of Perinatal Medicine in the Chinese Medical Association, all pregnant women are recommended to receive diagnostic test with a 75g OGTT test at 24-28 weeks of gestation and health education regarding GDM. ${ }^{42}$ The same is also recommended by the World Health Organization (WHO). ${ }^{43}$ Women diagnosed with GDM should be provided with lifestyle management composing medical nutrition therapy (MNT), weight management, exercise intervention and selfmonitoring of blood glucose (SMBG). If lifestyle management occurs ineffective, pharmacological intervention is necessary. ${ }^{24}$

MNT: The purpose of conducting MNT is to attain normal glycemic control without the development of ketosis and fetal compromises induced by reduced maternal blood glycose level, and maintain the adequate weight gain based on prenatal BMI. ${ }^{24}$ The mainstay of MNT for GDM patients, which is widely accepted, has been limited caloric intake. However, the extent of the limitation should be strictly 
controlled. On the one hand, a reduced caloric intake from $2400 \mathrm{kcal} / \mathrm{d}$ to $1200 \mathrm{kcal} / \mathrm{d}$ results in significant ketosis in women with GDM. ${ }^{44}$ On the other, though a caloric intake $>25 \mathrm{kcal} / \mathrm{kg}$ per day can prevent both ketosis and fetal growth compromise, the efficacy of this dietary intervention is not promising. ${ }^{45}$ Therefore, a reduction of caloric intake to approximately $24 \mathrm{kcal} / \mathrm{kg}$ per day is recommended by the American College of Obstetricians and Gynecologists (ACOG), along with the composition and distribution throughout the day. ${ }^{45}$

Maternal weight management: Weight monitoring plays a significant role in ensuring a recommended weight gain during pregnancy. However, due to the increasing incidence of obesity and glucose intolerance during pregnancy, the standard for appropriate weight gain during pregnancy has been repeatedly altered. Most recently, a revised guideline conducted by the Institute of Medicine (IOM) in America was released to assist weight management for pregnant women based on the individual primary weight (Table 1), and has been endorsed by the ACOG. ${ }^{46}$ The quality of the IOM guidelines was then examined in a study, demonstrating that the guidelines' recommended weight gain during pregnancy can significantly reduce the risks for several maternal-neonatal complications, such as pre-eclampsia, cesarean delivery and fetal macrosomia. ${ }^{47}$

Table 1

The guidelines of the institute of medicine (IOM) in America

\begin{tabular}{|ll|}
\hline Weight gain during pregnancy $\mathbf{( k g )}$ & Primary BMI $\left(\mathrm{kg} / \mathrm{m}^{2}\right)$ \\
\hline $12.5-18$ & $<19.8$ (underweight) \\
\hline $11.5-16$ & $19.8-26.0$ (healthy) \\
\hline $7-11.5$ & $26.0-29.0$ (overweight) \\
\hline$\leq 7$ & $\geq 29.0$ (obese) \\
\hline
\end{tabular}

Physical activity: For approximately $39 \%$ of GDM patients, physical activity is necessary in addition to MNT and weight managements for meeting targeted glucose level. ${ }^{48}$ Physical activity is capable of improving insulin sensitivity ${ }^{49}$ by boosting muscle glucose uptake and glycogen synthesis, ${ }^{50}$ therefore improve maternal glucose tolerance, which can to some extent avoid the use of insulin and other drugs. At least 30 minutes of physical activity on several days a week is recommended generally. ${ }^{50}$ If possible, more tailored exercise schedules based on individual condition might be more effective at glucose level and weight managements for GDM women. ${ }^{51}$

SMBG: In addition to dietary management and physical activity, SMBG is recommended to assist in glucose monitoring of pregnant women and determining whether pharmacological intervention is required. ${ }^{52}$ Frequent SMBG based on postprandial instead of pre-prandial monitoring has been reported to be associated with reduced adverse outcomes in insulin treated pregnant women. ${ }^{53}$ Moreover, 
continuous glucose monitoring (CGM), a novel technology allowing a 24-h monitoring of glucose levels, can significantly lower the risks of maternal-neonatal complications. ${ }^{54}$

\section{Pharmacological intervention:}

When dietary management and tailored physical activity fail to maintain the glycemic targets for pregnant women with GDM, pharmacological intervention is necessary.

Insulin: In most cases, insulin should be the first-line therapy for GDM. Types of insulin that can be used during pregnancy include short-acting and neutral protamine Hagedorn (NPH) insulin and rapid-acting analogues, which are lispro and aspart. The dose and regimen applied is determined based on individual severity of hyperglycemia in order to maintain glycemic targets. ${ }^{54}$ If the fasting glucose is elevated in the morning, NPH-insulin can be applied at an initial dose of 0.2 units $/ \mathrm{kg}$ body weight. If postprandial glycemic levels are increased, short-acting insulin can be used at doses of 1.5 units per $10 \mathrm{~g}$ per carbohydrate per breakfast and 1.0 units per $10 \mathrm{~g}$ per carbohydrate per lunch and dinner. If both pre-and postprandial glucoses are elevated, injection at a dosage of 0.9-1.0 units/kg can be applied four times a day. ${ }^{55}$ In cases of limited insulin provision, inaccurate insulin dosing, or severe needle phobia, glyburide can act as an ideal substitute. ${ }^{56}$

Metformin: Metformin is also one of the first-line treatments for GDM and T2DB to maintain glycemic control. The application of metformin can reduce the risks of gestational hypertension complications and maternal weight gain in GDM patients. Recent studies indicated that metformin can cross the placenta during pregnancy with an estimated rate of $10-16 \%,{ }^{57}$ exposing the fetus to high concentration of metformin which resulted in restriction of placental and fetal growth, followed by signs of catch up growth and obesity during childhood and inclination for cardiometabolic diseases later in life. ${ }^{58,59}$ Nevertheless, it is less likely to trigger severe neonatal hypoglycemia compared with insulin, since metformin neither stimulates pancreatic insulin release nor increases circulating insulin levels. ${ }^{60}$

Vitamin and omega-3 fatty acid co-supplementation: A recent study demonstrated that combined supplementation with vitamin D and omega-3 fatty acids for 6 weeks in GDM patients resulted in significantly improved outcomes, including suppressed glycemic and blood lipid levels, improved HOMA$\beta$ and insulin resistance. ${ }^{59}$ However, the clinical effects of the co-supplementation of vitamin and omega3 fatty acid remain poorly studied.

\section{Managements during labor and post-cesarean section}

Induction of labor (IOL): IOL is suggested when maternal or fetal risks associated with the process of pregnancy outweigh the risks associated with early delivery. ${ }^{61} \mathrm{IOL}$ conducted in early periods of pregnancy with GDM may reduce GDM-related maternal-neonatal complications, especially fetal macrosomia and stillbirth. ${ }^{62,63}$ However, it also carries the risks of other neonatal comorbidities, such as respiratory distress syndrome, mechanical ventilation, hypoglycemia and so on. ${ }^{64}$ 
Elective cesarean delivery: If the estimated fetal weight is over $4.0 \mathrm{~kg}$, an elective cesarean section is recommended by the International Federation of Gynecology and Obstetrics (FIGO) to prevent birth trauma ${ }^{65}$ Unfortunately, cesarean section comes with increased risks of wound hematoma, anesthetic complications, major puerperal infection and severe hemorrhage which may result in hysterectomy. Therefore, pragmatic perioperative treatments should be applied to minimize these surgical risks. Recent study suggested that vitamin $\mathrm{D}$ supplement in antenatal period can decrease the risk of cesarean section. ${ }^{66}$ During labor, insulin requirement is generally decreased and glucose infusion is even required in some cases, to prevent ketosis and provide for increased physical work and fasting time. ${ }^{67}$ For women who received antenatal pharmacological therapies, insulin infusion and 2-hour glycemic check is still required to control blood glucose levels. ${ }^{24}$

Breastfeeding: Studies suggested that GDM can increase the risk of breastfeeding failure. Low breastfeeding rates were found to be associated with neonatal weight loss and admission to NICU. ${ }^{68}$ It is recognized that intensive breastfeeding can improve weight and glucose tolerance during early postpartum period in obese women with GDM, therefore should be encouraged. ${ }^{69}$

Mobile health intervention and monitoring: Recent advances in medical devices coupled with artificial intelligence, Internet and remote-control technologies, such as mobile health application, allow mobile health intervention and self-monitor become reality. Evidences have verified the positive effects of the utilization of mobile health intervention in GDM patients. ${ }^{70}$

\section{Conclusion}

In conclusion, the application of rapid rehabilitation concept in enhanced recovery of cesarean section in pregnant women with GDM during perioperative period, can significantly reduce the risk of multiple maternal-neonatal complications. However, there is no precise guideline about the utilization of ERAS in cesarean section in GDM patients, hence the importance of exploring better ways to minimize the maternal-neonatal complications should be further stressed.

\section{Abbreviations}

GDM: Gestational diabetes mellitus

WOS: Web of Science

OGTT: oral glucose tolerance test

T2DM: type 2 diabetes mellitus

ERAS: Enhanced Recovery After Surgery

WHO: World Health Organization 
MNT: medical nutrition therapy

SMBG: self-monitoring of blood glucose

CGM: continuous glucose monitoring

NPH: neutral protamine Hagedorn

IOL: Induction of labor

FIGO: the International Federation of Gynecology and Obstetrics

\section{Declarations}

Ethics approval and consent to participate

Not applicable.

Consent for publication

Not applicable.

\section{Availability of data and materials}

Not applicable.

\section{Competing interests}

The authors declare that they have no competing interests.

\section{Funding}

Not applicable.

\section{Authors' contributions}

Qiuhong Yang decided the subject of this work. Aiwen Jian did the screening and reading of the enrolled articles and wrote the manuscript. All authors read and approved the final manuscript.

\section{Acknowledgements}

We would like to give thanks to Yundi Zhang for her kind help.

\section{References}


1. Hod M, Kapur A, Sacks DA, et al. The International Federation of Gynecology and Obstetrics (FIGO) Initiative on gestational diabetes mellitus: A pragmatic guide for diagnosis, management, and care. Int J Gynaecol Obstet. 2015;131 Suppl 3: S173-211.

2. Metzger BE, Coustan DR. Summary and recommendations of the Fourth International WorkshopConference on Gestational Diabetes Mellitus. The Organizing Committee. Diabetes Care. 1998;21 Suppl 2: B161-167.

3. Schneider S, Bock C, Wetzel M, Maul H, Loerbroks A. The prevalence of gestational diabetes in advanced economies. J Perinat Med. 2012;40: 511-520.

4. Alejandro EU, Mamerto TP, Chung G, et al. Gestational Diabetes Mellitus: A Harbinger of the Vicious Cycle of Diabetes. Int J Mol Sci. 2020;21.

5. Saeedi P, Petersohn I, Salpea P, et al. Global and regional diabetes prevalence estimates for 2019 and projections for 2030 and 2045: Results from the International Diabetes Federation Diabetes Atlas, 9th edition. Diabetes Research and Clinical Practice. 2019;157.

6. Catalano PM, Mclntyre HD, Cruickshank JK, et al. The hyperglycemia and adverse pregnancy outcome study: associations of GDM and obesity with pregnancy outcomes. Diabetes Care. 2012;35: 780-786.

7. Hoet JP, Lukens FD. Carbohydrate metabolism during pregnancy. Diabetes. 1954;3: 1-12.

8. Lenoir-Wijnkoop I, van der Beek EM, Garssen J, Nuijten MJC, Uauy RD. Health economic modeling to assess short-term costs of maternal overweight, gestational diabetes, and related macrosomia - a pilot evaluation. Frontiers in Pharmacology. 2015;6.

9. Hartling L, Dryden DM, Guthrie A, Muise M, Vandermeer B, Donovan L. Benefits and harms of treating gestational diabetes mellitus: a systematic review and meta-analysis for the U.S. Preventive Services Task Force and the National Institutes of Health Office of Medical Applications of Research. Ann Intern Med. 2013;159: 123-129.

10. Goldman M, Kitzmiller JL, Abrams B, Cowan RM, Laros RK, Jr. Obstetric complications with GDM. Effects of maternal weight. Diabetes. 1991;40 Suppl 2: 79-82.

11. Gorgal R, Goncalves E, Barros M, et al. Gestational diabetes mellitus: a risk factor for non-elective cesarean section. J Obstet Gynaecol Res. 2012;38: 154-159.

12. Leth RA, Uldbjerg N, Norgaard M, Moller JK, Thomsen RW. Obesity, diabetes, and the risk of infections diagnosed in hospital and post-discharge infections after cesarean section: a prospective cohort study. Acta Obstet Gynecol Scand. 2011;90: 501-509.

13. Scholtens DM, Kuang A, Lowe LP, et al. Hyperglycemia and Adverse Pregnancy Outcome Follow-up Study (HAPO FUS): Maternal Glycemia and Childhood Glucose Metabolism. Diabetes Care. 2019;42: 381-392.

14. Shasha H, Yin L, Zhigang Z, Jinhui T, Yikun Z, Caiyun Z. meta-analysis of clinical application of rapid rehabilitation surgery in caesarean section. Int J Nurs. 2017;36: 2452-2457.

15. Lykke JA, Langhoff-Roos J, Sibai BM, Funai EF, Triche EW, Paidas MJ. Hypertensive pregnancy disorders and subsequent cardiovascular morbidity and type 2 diabetes mellitus in the mother. 
Hypertension. 2009;53: 944-951.

16. Sullivan SD, Umans JG, Ratner R. Gestational diabetes: implications for cardiovascular health. Curr Diab Rep. 2012;12: 43-52.

17. Stanley JL, Cheung CC, Rueda-Clausen CF, Sankaralingam S, Baker PN, Davidge ST. Effect of gestational diabetes on maternal artery function. Reprod Sci. 2011;18: 342-352.

18. Dharmashankar K, Widlansky ME. Vascular endothelial function and hypertension: insights and directions. Curr Hypertens Rep. 2010;12: 448-455.

19. Demirpence S, Demirpence BI, Mese T, et al. Predictors of postnatal complications and congenital cardiac diseases in infants of mothers with pregestational and gestational diabetes. Turk Pediatri Ars. 2014;49: 299-306.

20. Group HSCR, Metzger BE, Lowe LP, et al. Hyperglycemia and adverse pregnancy outcomes. N Engl J Med. 2008;358: 1991-2002.

21. Barden A, Singh R, Walters BN, Ritchie J, Roberman B, Beilin LJ. Factors predisposing to preeclampsia in women with gestational diabetes. J Hypertens. 2004;22: 2371-2378.

22. Landon $\mathrm{MB}$, Spong $\mathrm{CY}$, Thom $\mathrm{E}$, et al. A multicenter, randomized trial of treatment for mild gestational diabetes. N Engl J Med. 2009;361: 1339-1348.

23. Osuagwu UL, Fuka F, Agho K, Khan A, Simmons D. Adverse Maternal Outcomes of Fijian Women with Gestational Diabetes Mellitus and the Associated Risk Factors. Reprod Sci. 2020;27: 2029-2037.

24. Kim C. Gestational diabetes: risks, management, and treatment options. Int J Womens Health. 2010;2: 339-351.

25. Naylor CD, Sermer M, Chen E, Sykora K. Cesarean delivery in relation to birth weight and gestational glucose tolerance: pathophysiology or practice style? Toronto Trihospital Gestational Diabetes Investigators. JAMA. 1996;275: 1165-1170.

26. Bellamy L, Casas JP, Hingorani AD, Williams D. Type 2 diabetes mellitus after gestational diabetes: a systematic review and meta-analysis. Lancet. 2009;373: 1773-1779.

27. Damm P. Future risk of diabetes in mother and child after gestational diabetes mellitus. Int $\mathrm{J}$ Gynaecol Obstet. 2009;104 Suppl 1: S25-26.

28. Damm P, Houshmand-Oeregaard A, Kelstrup L, Lauenborg J, Mathiesen ER, Clausen TD. Gestational diabetes mellitus and long-term consequences for mother and offspring: a view from Denmark. Diabetologia. 2016;59: 1396-1399.

29. Cheung NW, Byth K. Population health significance of gestational diabetes. Diabetes Care. 2003;26: 2005-2009.

30. Lucas A, Morley R, Cole TJ. Adverse neurodevelopmental outcome of moderate neonatal hypoglycaemia. BMJ. 1988;297: 1304-1308.

31. Catalano PM, Hauguel-De Mouzon S. Is it time to revisit the Pedersen hypothesis in the face of the obesity epidemic? American Journal of Obstetrics and Gynecology. 2011;204: 479-487. 
32. Zhang C, Qiu C, Hu FB, et al. Maternal plasma 25-hydroxyvitamin D concentrations and the risk for gestational diabetes mellitus. PLoS One. 2008;3: e3753.

33. Cordero L, Treuer SH, Landon MB, Gabbe SG. Management of infants of diabetic mothers. Arch Pediatr Adolesc Med. 1998;152: 249-254.

34. Bourbon JR, Farrell PM. Fetal lung development in the diabetic pregnancy. Pediatr Res. 1985;19: 253267.

35. Ullmo S, Vial Y, Di Bernardo S, et al. Pathologic ventricular hypertrophy in the offspring of diabetic mothers: a retrospective study. Eur Heart J. 2007;28: 1319-1325.

36. Balsells M, Garcia-Patterson A, Gich I, Corcoy R. Major congenital malformations in women with gestational diabetes mellitus: a systematic review and meta-analysis. Diabetes Metab Res Rev. 2012;28: 252-257.

37. Harder T, Aerts L, Franke K, Van Bree R, Van Assche FA, Plagemann A. Pancreatic islet transplantation in diabetic pregnant rats prevents acquired malformation of the ventromedial hypothalamic nucleus in their offspring. Neurosci Lett. 2001;299: 85-88.

38. Kelstrup L, Damm P, Mathiesen ER, et al. Insulin resistance and impaired pancreatic beta-cell function in adult offspring of women with diabetes in pregnancy. J Clin Endocrinol Metab. 2013;98: 37933801.

39. Johns EC, Denison FC, Norman JE, Reynolds RM. Gestational Diabetes Mellitus: Mechanisms, Treatment, and Complications. Trends Endocrinol Metab. 2018;29: 743-754.

40. Falavigna M, Schmidt MI, Trujillo J, et al. Effectiveness of gestational diabetes treatment: a systematic review with quality of evidence assessment. Diabetes Res Clin Pract. 2012;98: 396-405.

41. Viana LV, Gross JL, Azevedo MJ. Dietary intervention in patients with gestational diabetes mellitus: a systematic review and meta-analysis of randomized clinical trials on maternal and newborn outcomes. Diabetes Care. 2014;37: 3345-3355.

42. H Y. Guidelines for diagnosis and treatment of gestational diabetes mellitus (2014 edition). Chinese Journal of Obstetrics and Gynecology. 2014.

43. Petersmann A, Muller-Wieland D, Muller UA, et al. Definition, Classification and Diagnosis of Diabetes Mellitus. Exp Clin Endocrinol Diabetes. 2019;127: S1-S7.

44. Magee MS, Knopp RH, Benedetti TJ. Metabolic effects of 1200-kcal diet in obese pregnant women with gestational diabetes. Diabetes. 1990;39: 234-240.

45. Algert S, Shragg P, Hollingsworth DR. Moderate caloric restriction in obese women with gestational diabetes. Obstet Gynecol. 1985;65: 487-491.

46. American College of O, Gynecologists. ACOG Committee Opinion number 315, September 2005. Obesity in pregnancy. Obstet Gynecol. 2005;106: 671-675.

47. Langford A, Joshu C, Chang JJ, Myles T, Leet T. Does gestational weight gain affect the risk of adverse maternal and infant outcomes in overweight women? Matern Child Health J. 2011;15: 860865. 
48. Langer O, Berkus M, Brustman L, Anyaegbunam A, Mazze R. Rationale for insulin management in gestational diabetes mellitus. Diabetes. 1991;40 Suppl 2: 186-190.

49. Franz MJ, Bantle JP, Beebe CA, et al. Evidence-based nutrition principles and recommendations for the treatment and prevention of diabetes and related complications. Diabetes Care. 2003;26 Suppl 1: S51-61.

50. Perseghin G PT, Petersen K, et al. Increased glucose transportphosphorylation and muscle glycogen synthesis after exercise training in insulin-resistant subjects. N Engl J Med. 1996;335(18): 13571362.

51. Artal R, Lockwood CJ, Brown HL. Weight gain recommendations in pregnancy and the obesity epidemic. Obstet Gynecol. 2010;115: 152-155.

52. ACOG technical bulletin. Diabetes and pregnancy. Number 200--December 1994 (replaces No. 92, May 1986). Committee on Technical Bulletins of the American College of Obstetricians and Gynecologists. Int J Gynaecol Obstet. 1995;48: 331-339.

53. de Veciana M, Major CA, Morgan MA, et al. Postprandial versus preprandial blood glucose monitoring in women with gestational diabetes mellitus requiring insulin therapy. $\mathrm{N}$ Engl $\mathrm{J}$ Med. 1995;333: 1237-1241.

54. Yu F, Lv L, Liang Z, et al. Continuous glucose monitoring effects on maternal glycemic control and pregnancy outcomes in patients with gestational diabetes mellitus: a prospective cohort study. J Clin Endocrinol Metab. 2014;99: 4674-4682.

55. Cheung NW. The management of gestational diabetes. Vasc Health Risk Manag. 2009;5: 153-164.

56. Malek R, Davis SN. Pharmacokinetics, efficacy and safety of glyburide for treatment of gestational diabetes mellitus. Expert Opin Drug Metab Toxicol. 2016;12: 691-699.

57. Nanovskaya TN, Nekhayeva IA, Patrikeeva SL, Hankins GD, Ahmed MS. Transfer of metformin across the dually perfused human placental lobule. American Journal of Obstetrics and Gynecology. 2006;195: 1081-1085.

58. Lindsay RS, Loeken MR. Metformin use in pregnancy: promises and uncertainties. Diabetologia. 2017;60: 1612-1619.

59. Ekezie W, Dallosso H, Saravanan P, et al. Experiences of using a digital type 2 diabetes prevention application designed to support women with previous gestational diabetes Study protocol for a mixed methods exploratory investigation of aftercare services for gestational diabetes in women to develop a new patient-centred model in Germany: the GestDiNa_basic study Diabetes Management Delivery and Pregnancy Outcomes in Women with Gestational Diabetes Mellitus during the First Wave of the 2020 COVID-19 Pandemic: A Single-Reference Center Report The effect of combined supplementation with vitamin D and omega-3 fatty acids on blood glucose and blood lipid levels in patients with gestational diabetes

The use of mobile health interventions for gestational diabetes mellitus: a descriptive literature review

Interaction between Metformin, Folate and Vitamin B(12) and the Potential Impact on Fetal Growth

Page 14/16 
and Long-Term Metabolic Health in Diabetic Pregnancies. LID - 10.3390/ijms22115759 [doi] LID 5759

Effects of vitamin and omega-3 fatty acid co-supplementation on blood glucose in women with gestational diabetes mellitus: A protocol for systematic review and meta analysis Comparison of Pregnancy Outcomes Using Different Gestational Diabetes Diagnostic Criteria and Treatment Thresholds in Multiethnic Communities between Two Tertiary Centres in Australian and New Zealand: Do They Make a Difference? LID - 10.3390/ijerph18094588 [doi] LID - 4588 Maternal and neonatal outcomes after energy-restricted diet for women with gestational diabetes mellitus: A systematic review and meta-analysis of randomized controlled trials Maternal and neonatal glycaemic control after antenatal corticosteroid administration in women with diabetes in pregnancy: A retrospective cohort study Nutrients that modulate gestational diabetes mellitus: A systematic review of cohort studies Jan 2019-Jan 2020.

60. Feng $\mathrm{Y}$, Yang $\mathrm{H}$. Metformin - a potentially effective drug for gestational diabetes mellitus: a systematic review and meta-analysis. J Matern Fetal Neonatal Med. 2017;30: 1874-1881.

61. Bulletins ACoP. ACOG Practice Bulletin. Chronic hypertension in pregnancy. ACOG Committee on Practice Bulletins. Obstet Gynecol. 2001;98: suppl 177-185.

62. Boulvain M, Senat MV, Perrotin F, et al. Induction of labour versus expectant management for largefor-date fetuses: a randomised controlled trial. Lancet. 2015;385: 2600-2605.

63. Rosenstein MG, Cheng YW, Snowden JM, Nicholson JM, Doss AE, Caughey AB. The risk of stillbirth and infant death stratified by gestational age in women with gestational diabetes. American Journal of Obstetrics and Gynecology. 2012;206: 309 e301-307.

64. Clark SL, Miller DD, Belfort MA, Dildy GA, Frye DK, Meyers JA. Neonatal and maternal outcomes associated with elective term delivery. American Journal of Obstetrics and Gynecology. 2009;200: 156 e151-154.

65. Hod M, Kapur A, Sacks DA, et al. The International Federation of Gynecology and Obstetrics (FIGO) Initiative on gestational diabetes mellitus: A pragmatic guide for diagnosis, management, and care(). Int J Gynaecol Obstet. 2015;131 Suppl 3: S173-S211.

66. Saha S, Saha S. A comparison of the risk of cesarean section in gestational diabetes mellitus patients supplemented antenatally with vitamin D containing supplements versus placebo: A systematic review and meta-analysis of double-blinded randomized controlled trials. J Turk Ger Gynecol Assoc. 2020;21: 201-212.

67. Jovanovic L. Glucose and insulin requirements during labor and delivery: the case for normoglycemia in pregnancies complicated by diabetes. Endocr Pract. 2004;10 Suppl 2: 40-45.

68. Verd S, de Sotto D, Fernandez C, Gutierrez A. The Effects of Mild Gestational Hyperglycemia on Exclusive Breastfeeding Cessation. Nutrients. 2016;8.

69. Yasuhi I, Yamashita H, Maeda K, et al. High-intensity breastfeeding improves insulin sensitivity during early post-partum period in obese women with gestational diabetes. Diabetes Metab Res Rev. 
2019;35: e3127.

70. Zahmatkeshan M, Zakerabasali S, Farjam M, Gholampour Y, Seraji M, Yazdani A. The use of mobile health interventions for gestational diabetes mellitus: a descriptive literature review. J Med Life. 2021;14: 131-141. 